\title{
An on-site teaching laboratory in a village damaged by the 2009 Abruzzo earthquake
}

\author{
L. Giresini \\ University of Pisa \\ linda.giresini@unipi.it bttps://orcid.org/0000-0001-6913-7468
}

\author{
M. Sassu \\ University of Cagliari \\ msassu@unica.it bttps:/ / orcid.org/0000-0002-3414-2360
}

\begin{abstract}
This paper illustrates a two-year program of summer internships that involved forty students from the School of Engineering (University of Pisa) in 2010-2011. The activity consisted in a systematic survey of damages occurred in a village after the 2009 Abruzzo earthquake and in the preparation of documents addressed to a reconstruction plan. The historical center of San Pio delle Camere (1000 inhabitants) was fully surveyed, including about 140 hypogeal sites. Each student spent at least one month in these activities, funded by study grants provided by the Tuscany Region. Teams of two-three students performed well-defined work packages, led by a tutor, who established roles and functions. The students discussed the progress made preparing a weekly report. Moreover, preliminary structural analyses were carried out to assess the seismic vulnerability of some relevant buildings, fully available to the students. The main results were published in a book presented in a workshop. Most of the results were used to set up the official reconstruction plan of the village. During this on-site laboratory, the students could experience the effects of that destructive earthquake on the population, visiting also the damaged surrounding towns and seeing with their own eyes many cases of structural collapses.
\end{abstract}

KEYwORDS. Internships; Abruzzo earthquake; Teaching laboratory; Educational activity; Structural analysis; Survey of damages.
OPEN ACCESS

Citation: Giresini, L., Sassu, M An on-site teaching laboratory in a village damaged by the 2009 Abruzzo earthquake, Frattura ed Integrità Strutturale, 46 (2018) 178-189.

Received: 31.05 .2018

Accepted: 27.08 .2018

Published: 01.10 .2018

Copyright: (C) 2018 This is an open access article under the terms of the CC-BY 4.0, which permits unrestricted use, distribution, and reproduction in any medium, provided the original author and source are credited.

\section{INTRODUCTION}

fter the 2009 Abruzzo earthquake, the Tuscany region funded a two-year program of summer internships in one of the towns damaged by the main seismic shock, San Pio delle Camere (Fig. 1). During the summer of the years 2010 and 2011, about forty students from the University of Pisa were involved in activities of survey, monitoring 
and analysis of buildings in this village. Each student participated for four weeks in the areas struck by the earthquake, taking advantage of the opportunity of an open-air teaching laboratory. Indeed, this was an important educational occasion for students to observe real-life behavior of constructions under seismic actions, and how an erroneous structural conception can lead to relevant disasters. The students could face issues typical of existing masonry buildings and of particular historical structures, hypogean sites, called "Camere" (from which the town name derives). The teams classified over a hundred building blocks, recognizing the building types that better performed over the shock and those that were affected by collapses.

During the internship several inspections took place in some nearby small cities (Paganica, Onna, Barisciano, San Demetrio nei Vestini, Fossa etc., Fig. 2) and the historic center of L'Aquila. In addition, the students participated in surveys to observe interventions of retrofitting after earthquake, such as temporary houses, temporary schools, new buildings with seismic isolators. The students interacted with the inhabitants, the authorities and the technical offices, acquiring a socioeconomic knowledge of the site. They experienced the difficulties faced by the local authorities in the survey of seismic damages and in programming a reconstruction plan. It is worth noticing extremely positive results obtained with such an experience: the high number of surveys of buildings with different types of collapse, the close relationships with the inhabitants, the close connections with the colleagues represented a relevant human and professional experience for both the students and the tutors that led them.
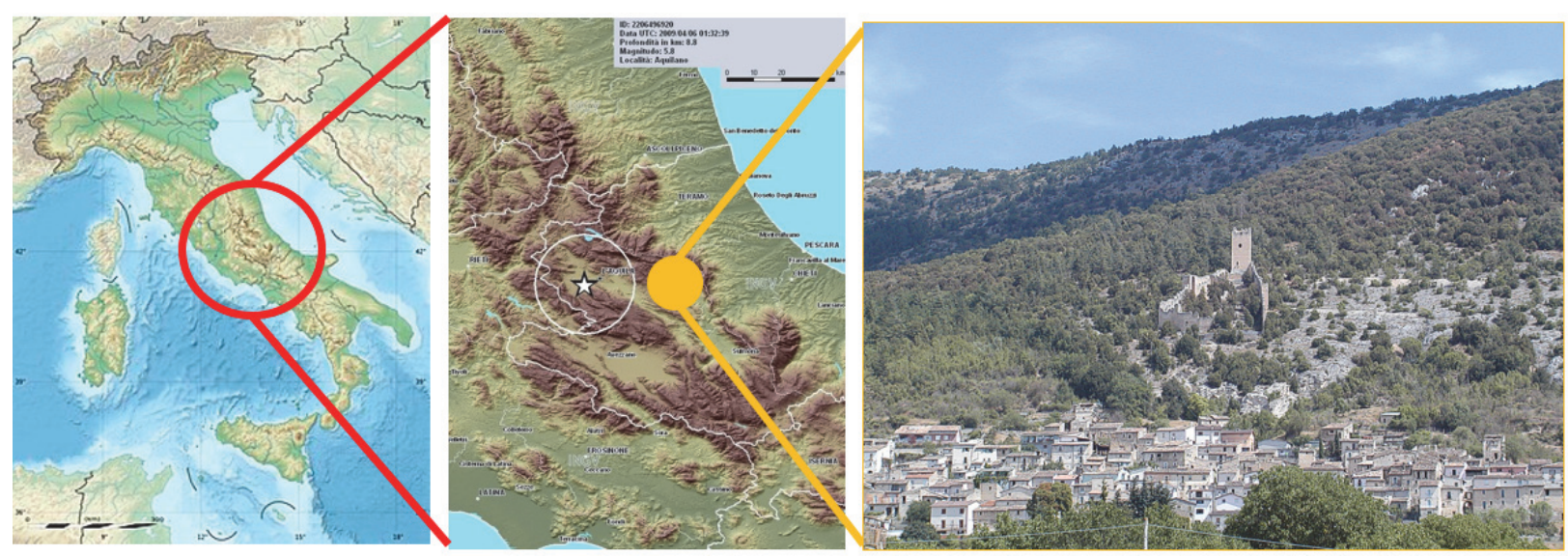

Figure 1: San Pio delle Camere village: the on-site teaching laboratory for students.

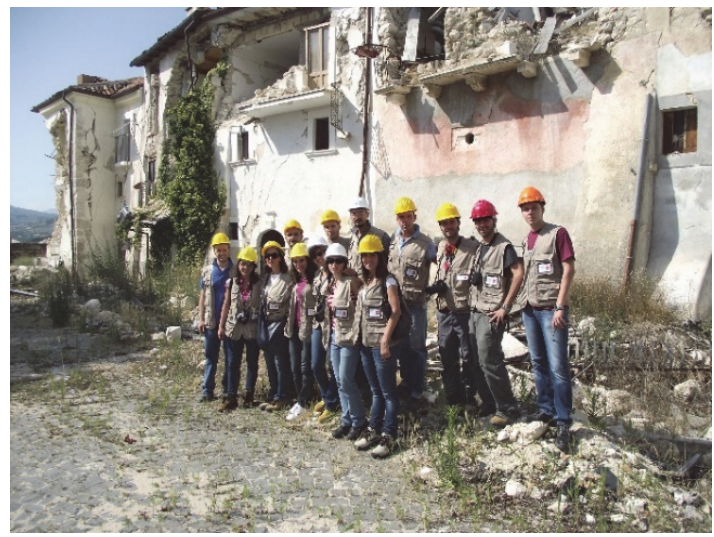

Figure 2: A part of the student group selected for the internship during a survey.

\section{THE DAMAgES OF THE 2009 ABRUZZO EARTHQUAKE}

uring the night of April 6th, 2009, a main shock rated 5.9 on the Richter scale (M6.3) occurred in the Abruzzo Italian Region. This shock caused devastation, with 286 deaths and 1173 injured. San Pio delle Camere, $25 \mathrm{~km}$ far away from the epicenter, was made of 2-3 storey masonry buildings, built according to the schemes B-C of Fig. 
3 a due to the sloping ground condition. A considerable amount of houses in the city centre were of the so-called "Profferlo" type [1]: an external staircase and a multi-functional house (Fig. 3b). The basement was often used for storage or as farm recovery, while the other floors were used for residential purposes. The newest part of the village, mainly made of r.c. buildings, was not damaged.

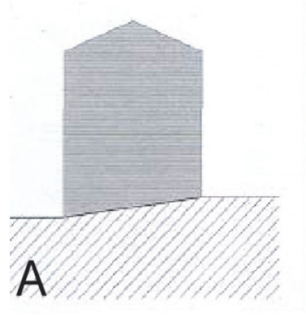

B

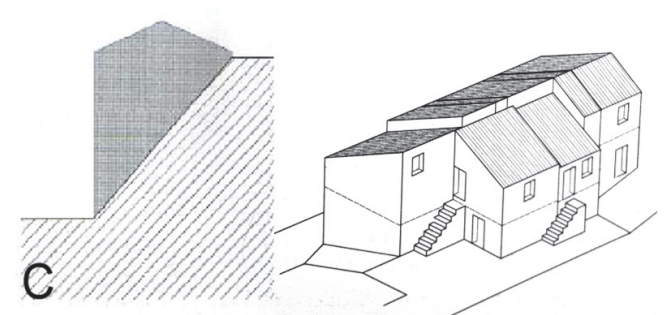

(b)

Figure 3: Buildings location in case of ground natural slope [1] (a); "Profferlo" house typical scheme [1](b).

The earthquake damages showed the relevant role of the soil seismic amplification: similar buildings, located at the same distance from the epicenter but with different soil characteristics, had shown strongly different damages. While San Pio delle Camere - built over rock - was not heavily damaged by the earthquake, the nearby town, Castelnuovo, was affected by a significant seismic shock amplification. The San Pio subsoil is characterized by a carbonate bedrock overlaid by breccias in the upper part of the village and alternative layers of continental drifts of silts and clay in the lower part [2,3]. The area nearby San Pio is built over an alluvial soil. Thus, the need of analyzing in detail the seismic micro-zonation arose to better address the interest of future housing projects. In particular, greater damages occurred in buildings with irregular masonry, weak mortar and floors such as vaults or poorly connected beams.

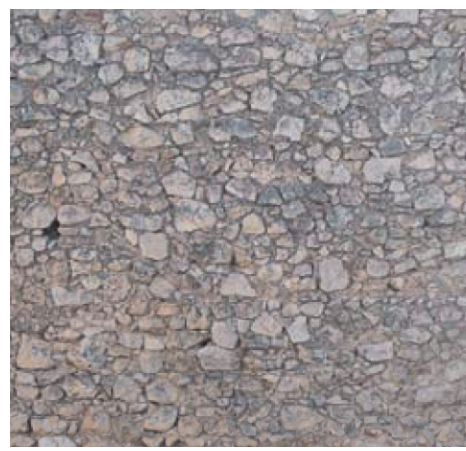

(a)

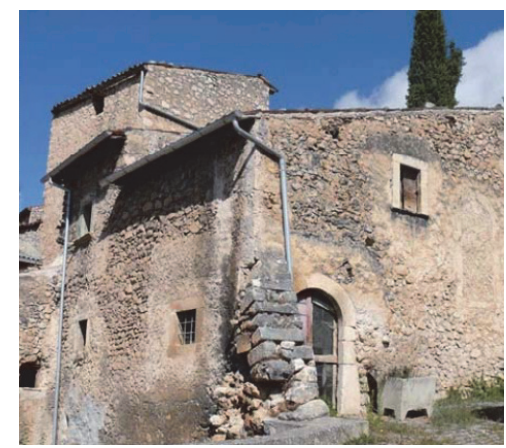

(b)

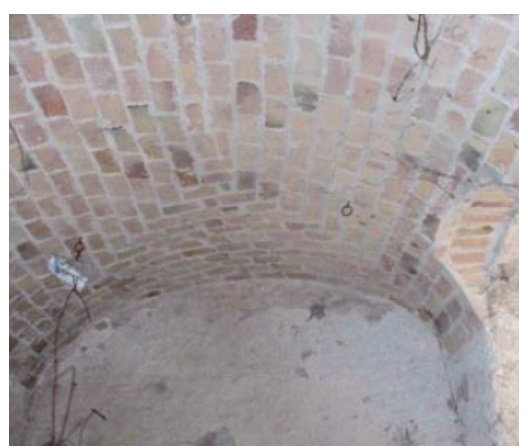

(c)

Figure 4: Old masonry texture (a); typical house in the city centre (b); masonry vault (c).

Masonry of poor quality was mainly made of small size stones with irregular shape (Fig. 4a,b), without headers or transverse connections. Local mechanisms of out-of-plane rigid block modes and collapse of external leafs were detected [4]. Other relevant damages influenced heavy roofs in clay and r.c. diaphragms, besides flexible roofs such as vaults (Fig. 4c). More extensive failures were surveyed in some buildings with hypogeal cavities, as illustrated in the next paragraphs. The buildings with masonry made of concrete blocks masonry, good quality mortar, steel ties and light timber roofs were less damaged.

\section{EDUCATIONAL ACTIVITIES}

\section{The internship framework}

A crucial aspect of the internship was related to its organization: the selected forty students (twenty each year), were divided in eight teams with a time schedule well defined for properly covering the working period (Fig. 5).

The work groups were constantly supported by teams of tutors, research assistants and PhD students, under the guidance of one one of the authors of this paper. 


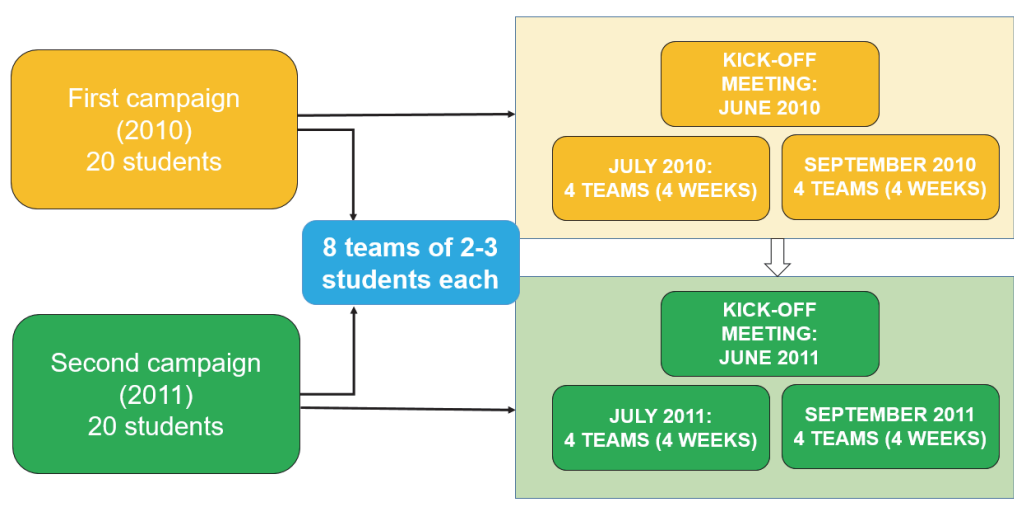

Figure 5: Internships framework.

The activity program mainly involved two steps: the survey of structural building blocks and a careful survey of earthquake damages, starting from the analysis of previously compiled forms designed by the Civil Protection Department. This analysis allowed to classify in each block of buildings the typologies of damages and the safety level. Collateral activities, such as inspections in the nearby damaged areas, alto took place (Fig. 6).

Two books [5,6] and conferences were the result of those activities. The participants were directly engaged in the dissemination of results. Each team prepared a specific chapter of the book under the guidance of team tutors.

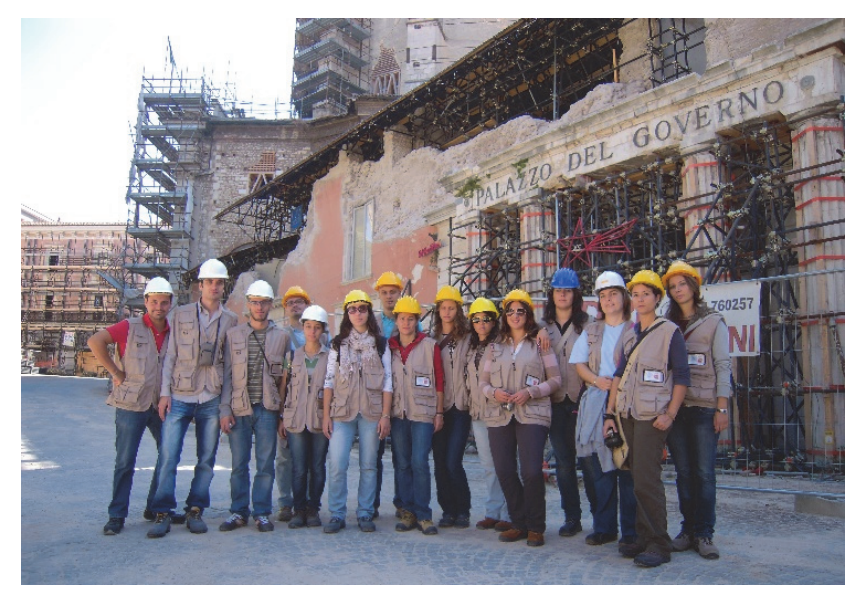

Figure 6: Inspection in L'Aquila with a group of students.

\section{FIRST CAMPAIGN: SURVEY AND DAMAGE CLASSIFICATION}

\section{Survey of damages and form-based assessment}

he activity program started in Summer 2010 with the survey of building blocks, composed by "structural units" (S.U.) and "units of minimum intervention" (U.M.I.). The U.M.I.s were defined as minimum sets of S.U., structurally independent components of building blocks, to better organize the reinforcement activities. By identifying the S.U., the students could practice conceptual design of individual structures. Moreover, they could also reflect about an optimization of structural interventions from a technical and economic point of view, through the analysis of the U.M.I.s. The students spent the first two-three weeks of the first campaign in a systematic survey of damages, most of them light or moderate cracks in masonry buildings of the historic center, as discussed in the previous paragraph (Fig. 7). The main rehabilitation activities before and after the earthquake were also classified. The use of steel tie-rods, reinforced concrete plaster, curbs, metal beams was observed, but the effectiveness depended on the type of building, soil and construction in accordance with the best practices. They also made inspections in the newer part of the town, with r.c. buildings not significantly damaged, due to the lower soil amplification. The students could relate the damages of masonry buildings to 
their poor quality, both in terms of material and construction techniques [7]. Moreover, improper retrofitting techniques had been adopted before the earthquake, worsening a potentially dangerous building status. The students realized that (i) erroneous interventions could worsen a situation and that (ii) the use of simple anti-seismic devices, such as steel tie-rods on regular masonry (with regular units), could strongly improve the building response under dynamic actions. Indeed, the buildings with those elements showed less pronounced out-of-plane damage and performed much better without significant cracking. For what concerns point (i), it should be pointed out that the team tutors systematically explained why some interventions, e.g. the substitution of a timber diaphragms with an r.c. floor, could aggravate the building response in case of a seismic shock. In this way the building dynamic features could vary such a way that the overall structural stiffness increases and the seismic action is amplified.

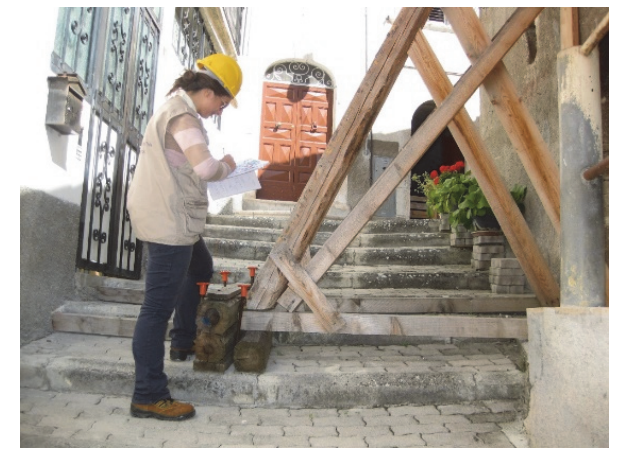

(a)

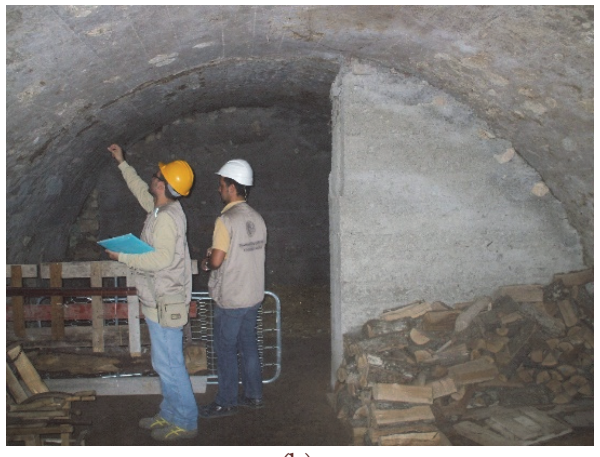

(b)

Figure 7: Students surveying structural features and damages of a building (a) and an hypogeal structure (b).

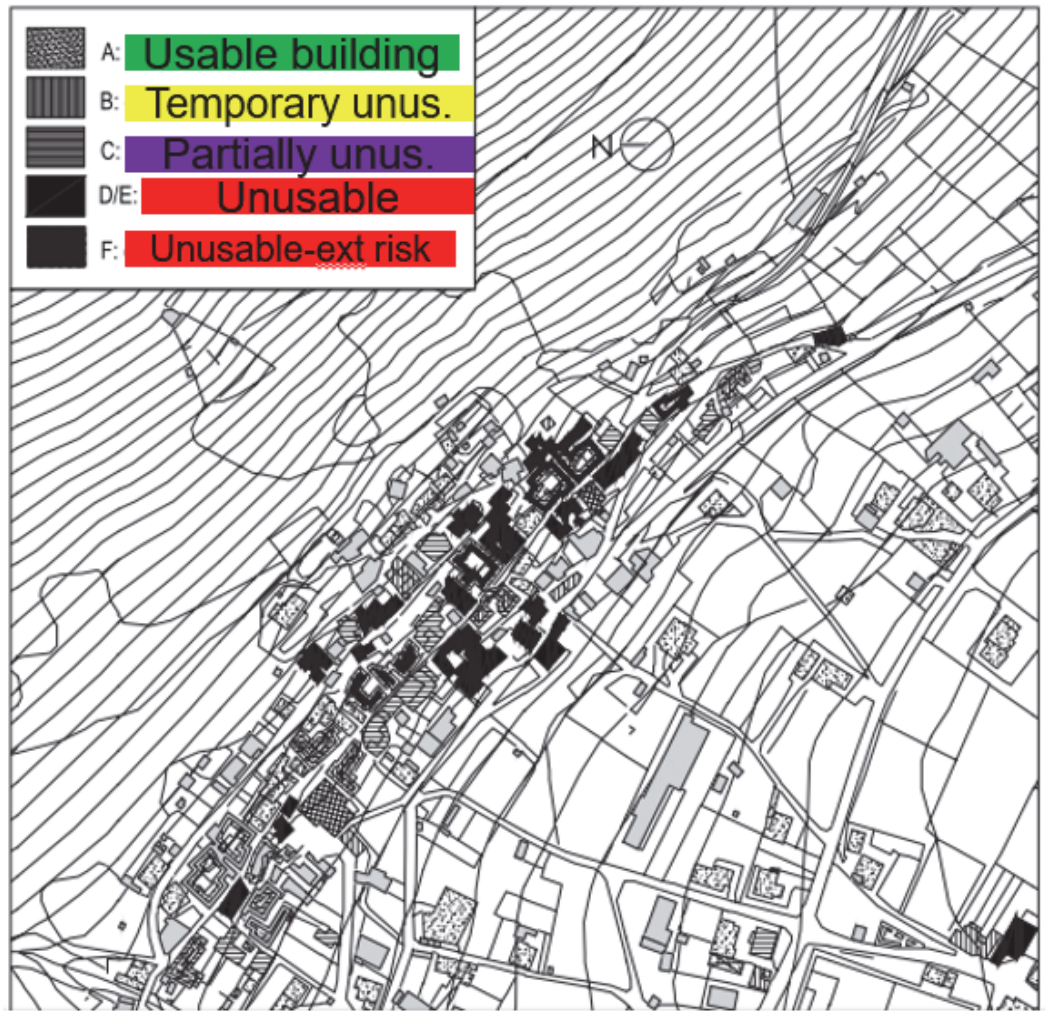

Figure 8: Classification of building blocks depending on their hazard level.

Some historic buildings, such as the San Pietro Celestino Church, were declared unusable due to the collapse of the bell tower and an incipient overturning of the main façade. Other cases were also declared unusable for the external risk caused by adjacent buildings (Fig. 9). 


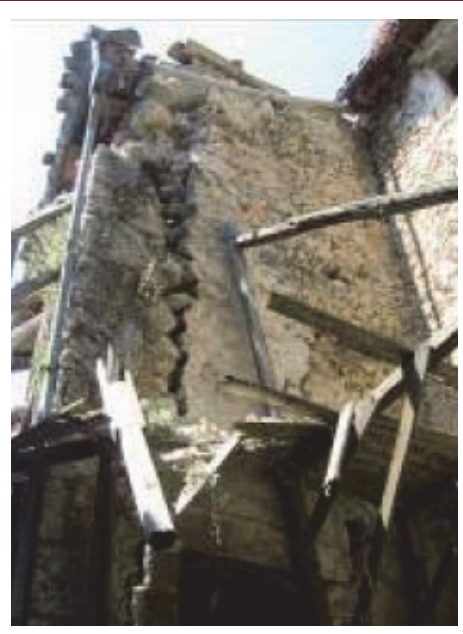

(a)

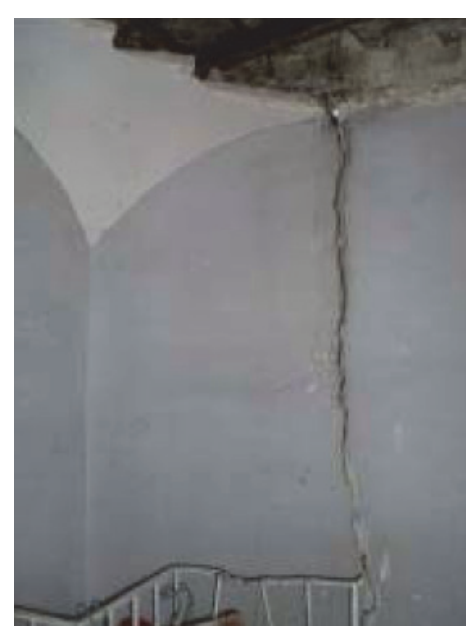

(b)

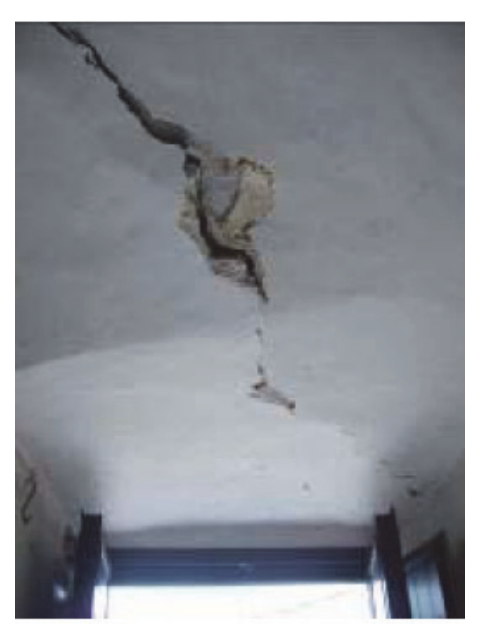

(c)

Figure 9: Masonry façade overturning (a); partial vault collapse (b); deep vault crack due to shear action (c).

After this phase, the students analyzed the forms previously compiled by technicians right after the earthquakes.

These forms (called AeDES, Agibilità e Danno nell'Emergenza Sismica = Usability and Damage in Seismic Emergency [8]), contain data regarding site and structural properties, the damage level of structural and non-structural elements, qualitative information concerning soil and foundations. The forms also consider external risk due to other constructions, the mean vulnerability level and the indication of some short-term countermeasures (e.g. temporary scaffolding, supports) to promptly reduce risk in the post-earthquake phase. The students could infer from these forms, made available by the local authorities, a map of the damages and therefore the vulnerability useful for an assessment of a seismic amplification (Fig. 8). It is worth noticing high educational value of this experience for the students of verifying with their own eyes all these aspects related to the survey of damages.

\section{Hypogeal structures}

San Pio delle Camere is characterised by horizontal underground hypogeal structures (caves with chambers) (Camere, in Italian, Fig. 3) excavated under the buildings in the rock or in the sedimentary alluvium. This structural feature was very interesting to be considered by the students, which had the possibility of understanding its role on the structural behaviour of whole building blocks. In particular, two teams of students systematically classified over 150 hypogeal structures (Fig. 10), identifying three main typologies of chambers:

- Type 1: the cave is made of three components: the first chamber is located beneath the building, generally a plastered clay bricks barrel vault; the second chamber is located right behind the first chamber, it is excavated and covered by a barrel vault built using irregular stones; and the third chamber is usually large and high (Fig. 11a);

- Type 2: same as Type 1, but without the second chamber: a large and high chamber is directly excavated in the ground behind the building, and has a few natural recesses and secondary chambers (Fig. 11b);

- Type 3: multi-level chambers of types 1 and 2. This typology is most frequent, due to the numerous construction activities which occurred during a few decades. In this case, the chambers can be up to 30 meters deep. Sometimes, reinforced arches are built beneath other structures, but are offset with respect to the upper walls (Fig. 11c).

An example of a façade with entrance to the hypogeal structures is shown in Fig. 11d.

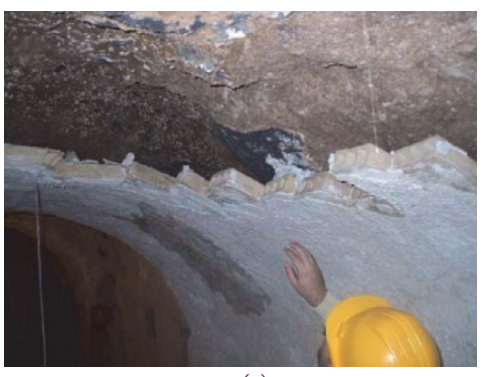

(a)

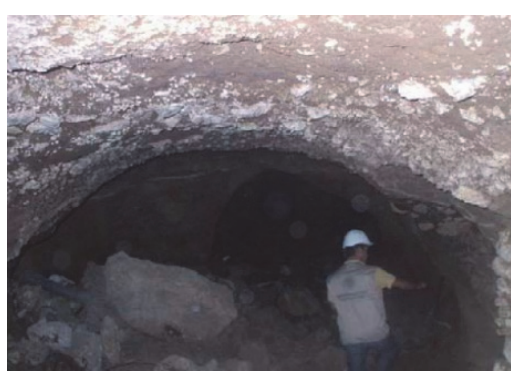

(b)

Figure 10: Qualitative survey of the hypogeal structures: assessment of the structural status (a); material and humidity level (b). 
The first team analysed the main structural characteristics of these chambers, such as the soil type and the humidity level (Fig. 10a, b). Clay alluvium of red colour was mainly identified, with discrete cohesion and compact.

Due to the lack of instrumentation, the survey was performed in qualitative but systematic way, which is sufficient for general information. The students could associate the chamber qualitative features to their structural behaviour: their stability is due to some low tensile material strength and plastic behaviour.

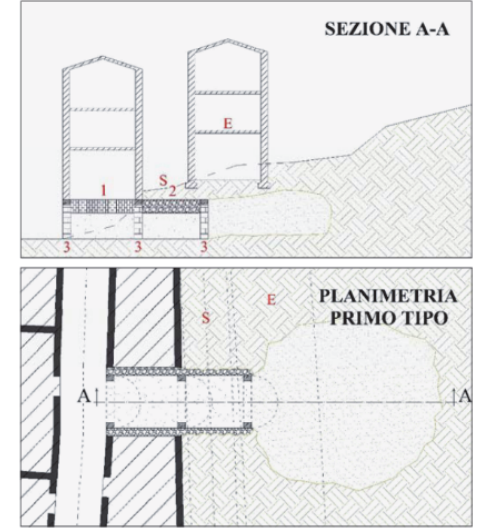

(a)

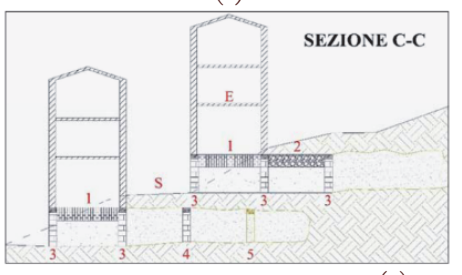

(c)

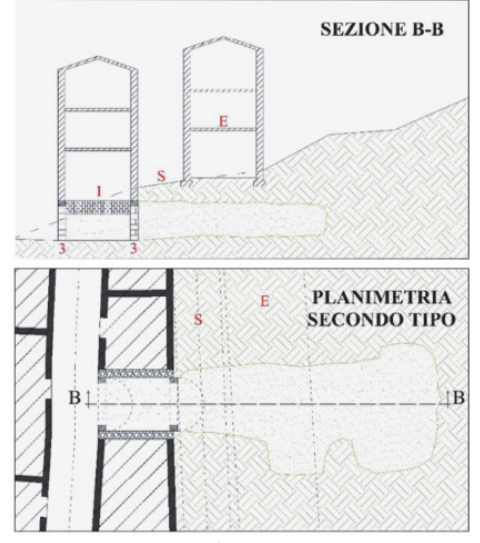

(b)

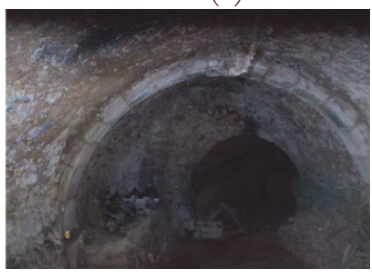

(d)

Figure 11: Technical survey of the hypogeal structures: type 1 (a); type 2 (b); type 3 (c); example of façade with entrance to chambers (d).

Through visual inspection and collection of information by the owners, the humidity level seen in many chambers significantly rose up after the earthquake. Indeed, in the past the chambers were more or less dry or slightly humid. In many surveys, the material was wet to the touch and plastic. In a few cases, leakage of water was observed, probably caused by failures in the water supply network or small soil cracks due to the ground motion. For this reason, some chamber covering collapsed at few locations.

Moreover, the students analysed static and technical issues related to the chambers. They investigated the types of loads acting on the chambers, and identified several types of loads, such as concentrated (due to columns), uniformly distributed (walls), and non-uniformly distributed (arches). In many cases, they could observe the chosen retrofitting techniquesbased on the load type: continuous walls provided to counteract the load of the upper wall \#2 (Fig. 12a) by a new longitudinal wall (Fig. 12b).

Another strengthening technique was in the form of a transverse arch balancing the load due to a continuous wall in transverse direction (Fig. 12c,d).

The second team of students developed a practical data sheet to classify the hypogeal structures (Fig. 13). The data sheet comprises eight sections: (I) identification data (address, owners name) and level of inspection; (II) geometrical data and 
coating, distinguishing the type of chamber; (III) the soil type; (IV) the general status of the structure (water, humidity level, collapses); (V) features of the building over the hypogeal structure considered; (VI) usability level provided by the AEDES forms, previously described and a final judgement of the structural condition, with five levels of damage; (VII) pictures, technical drawing and relevant notes, such the presence of failures, water leakage, etc.

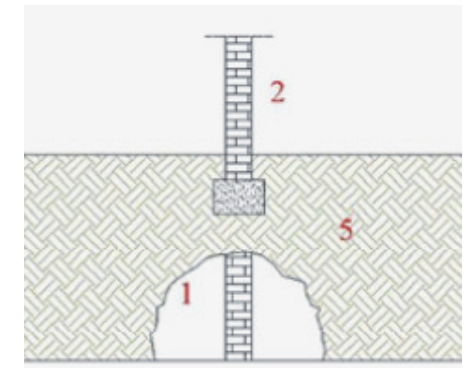

(a)

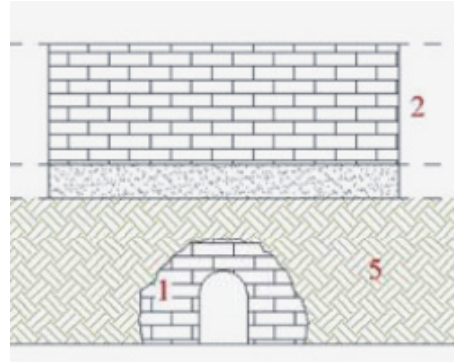

(c)

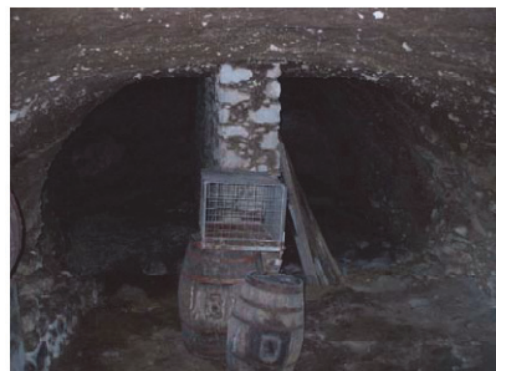

(b)

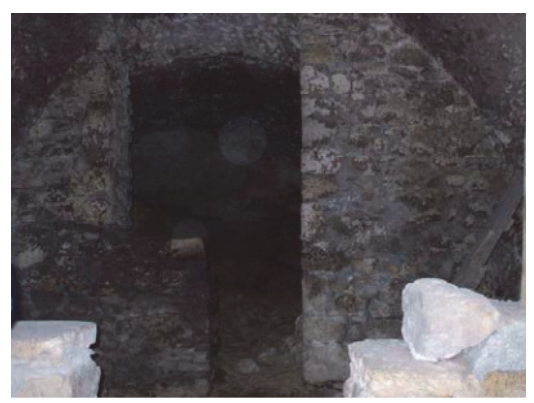

(d)

Figure 12: Schematization of loads and support structures: continuous wall (a, b); transverse arch (c,d).

\section{SECOND CAMPAIGN: ANALYSIS OF REAL DATA AND PROPOSALS OF RETROFITTING ACTIVITIES}

he second campaign, which took place in Summer 2011, involved other half of the group (twenty students in total). Their activities were related to the elaboration of the data collected in 2010, completion of several surveys of masonry building blocks and hypogeal structures, and to structural analyses on buildings. This section illustrates the seismic analyses performed on selected buildings to increase the awareness of students of their professional role after graduation.

\section{Local seismic analyses}

The tutors selected some relevant case studies among the buildings surveyed in San Pio delle Camere village. The selection criterion was related to the amount of information available for each case and to the strategic importance of the building for the municipality.

The teams of students had to calculate the minimum horizontal forces capable of triggering the failure mechanism. For that purpose the students had to collect information regarding the geometry of the macro-element and the applied loads (e.g. specific weight of masonry, floor loads, thrust forces due to arches, etc). This process is a straightforward exercise for civil engineering students, but very useful for understanding the relevance of simple calculations for obtaining preliminary but relevant information regarding the safety level of the macro-element; this is due to the higher vulnerability of out-ofplane as opposed to in-plane failure modes.

\section{$V$ ulnerability index and risk index assessment}

The strategy of using simplified methods to quickly evaluate seismic vulnerability of urban areas is commonly adopted for historic centers [9-12]. In the present study, the students assessed the vulnerability index for selected buildings using the information available about the survey made in the first campaign. The students collected the data by filling out a standard form using a data sheet made available by the Marche Region [13].

Initially, the students had to identify relevant structural parameters (material, regular/irregular building, foundation, floors and roof types, presence of good connections between floors and vertical structural elements). The scores associated with 
these parameters allowed to calculate a scaled vulnerability index and the corresponding capacity peak ground acceleration which is required to initiate structural failure. The combination of capacity peak ground acceleration and demand peak ground acceleration governed the final risk index for the building.

The vulnerability index was calculated for the S.U., the U.M.I. and the building blocks. In this way, the students gained confidence by using huge amount of data collected in the previous campaign and processing it to compile a priority order of interventions useful for local authorities.

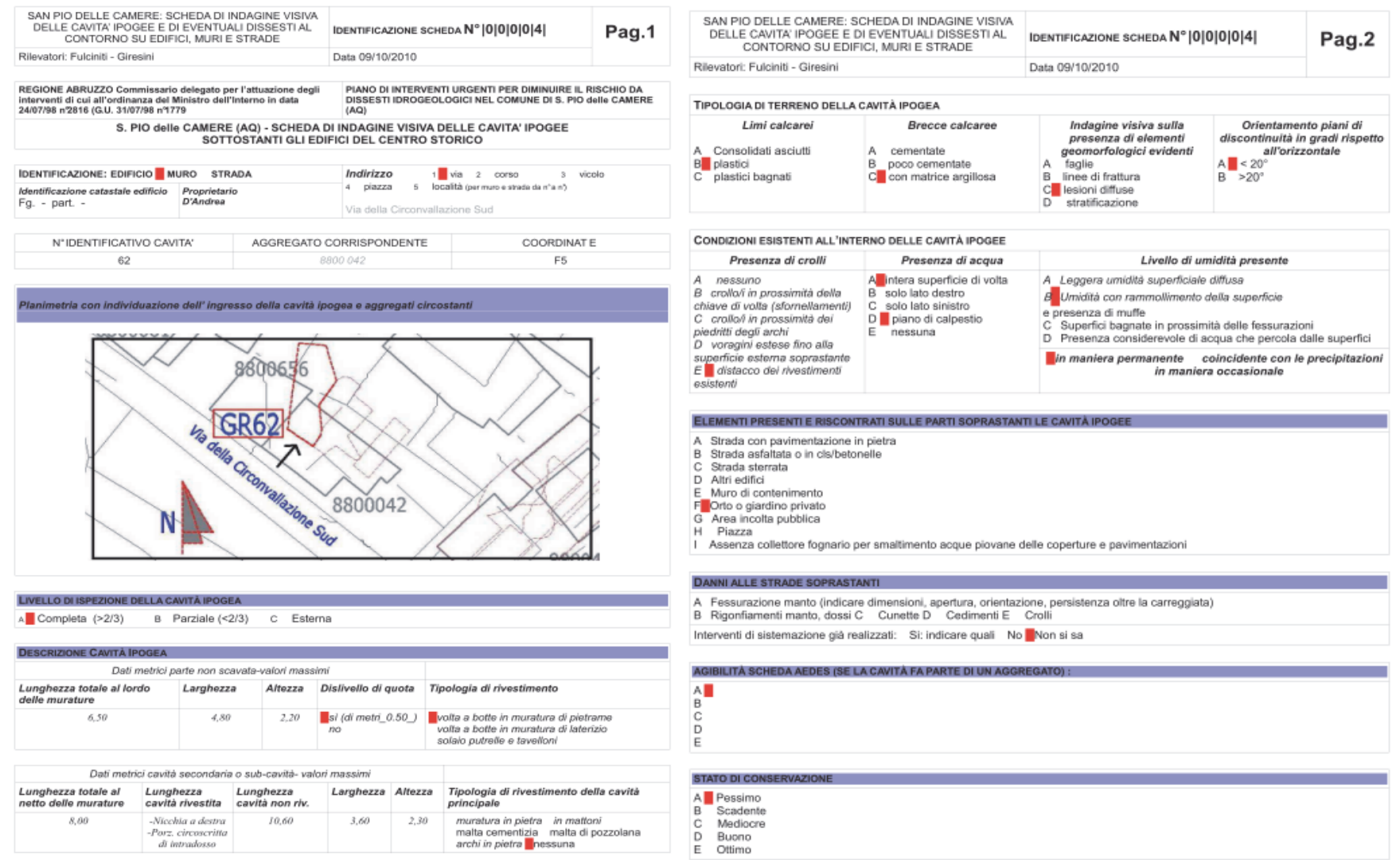

Figure 13: Student-developed data sheet for the classification of hypogeal structures.

\section{Global and local seismic analyses}

The last step of the campaign, performed by three student teams, was the structural analysis of selected case studies, such as schools and other strategic buildings. Simple linear dynamic analyses with computer-based programs were carried out (Fig. 14). For this purpose, the students dealt with the computation of the response spectra corresponding to the main seismic shock record. Moreover, the computed spectra were compared to that provided by the Italian Standards, confirming the results available in the literature [22] (Fig. 15) and the students verified that the spectrum given by the codes was underestimated. In this manner, they had an opportunity to directly apply their knowledge related to seismic analysis (similar to the real professional practice), and also gain a deeper perception of the issue of analyzing real structures through physical models.

Another activity consisted in performing kinematic analyses of several buildings damaged by the earthquake using the methods described in [14]. Firstly, the structural units were identified and the crack patterns with the activated damage mechanisms were detected (Fig. 16). The more evident damage mechanisms were afterwards analysed to obtain the actual peak ground acceleration (PGA) which was recorded during the earthquake. The methodology concerned the application of simple kinematics of rocking block models, taking into account the horizontal inertial forces and the stabilizing effects of the self-weight and of any tie rods [15-19]. In some cases, the kinematics was applied to thrusting arches and vaults, with the results later used for research purposes [20-21].

This approach enabled us to consider each building as a "peak ground accelerometer" and reveal the actual PGAs at each location within the city center (Fig. 17). The PGA distribution was relatively uniform with the minimum of $0.07 \mathrm{~g}$, the maximum of $0.12 \mathrm{~g}$, and an average value of $0.094 \mathrm{~g}$. 


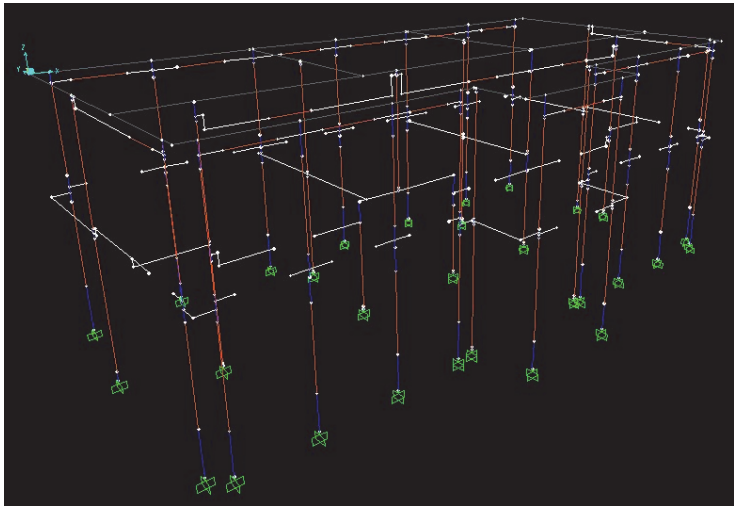

(a)

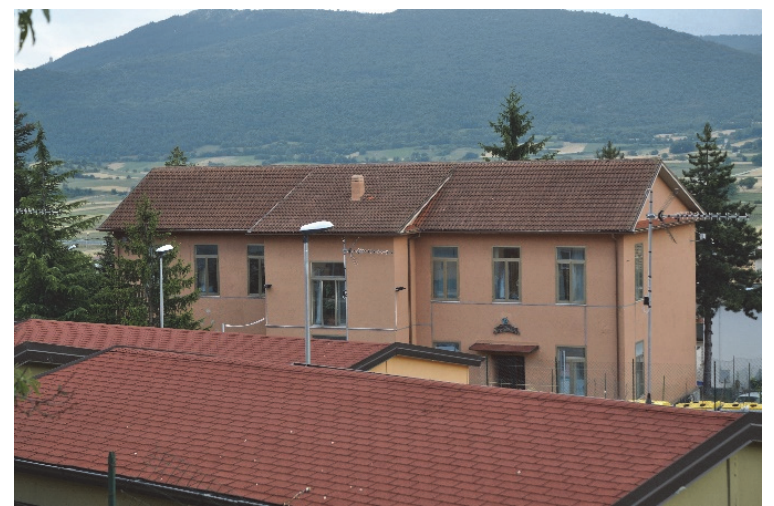

(b)

Figure 14: Case study of a municipality building: finite element model of a frame structure (a); actual building (b).

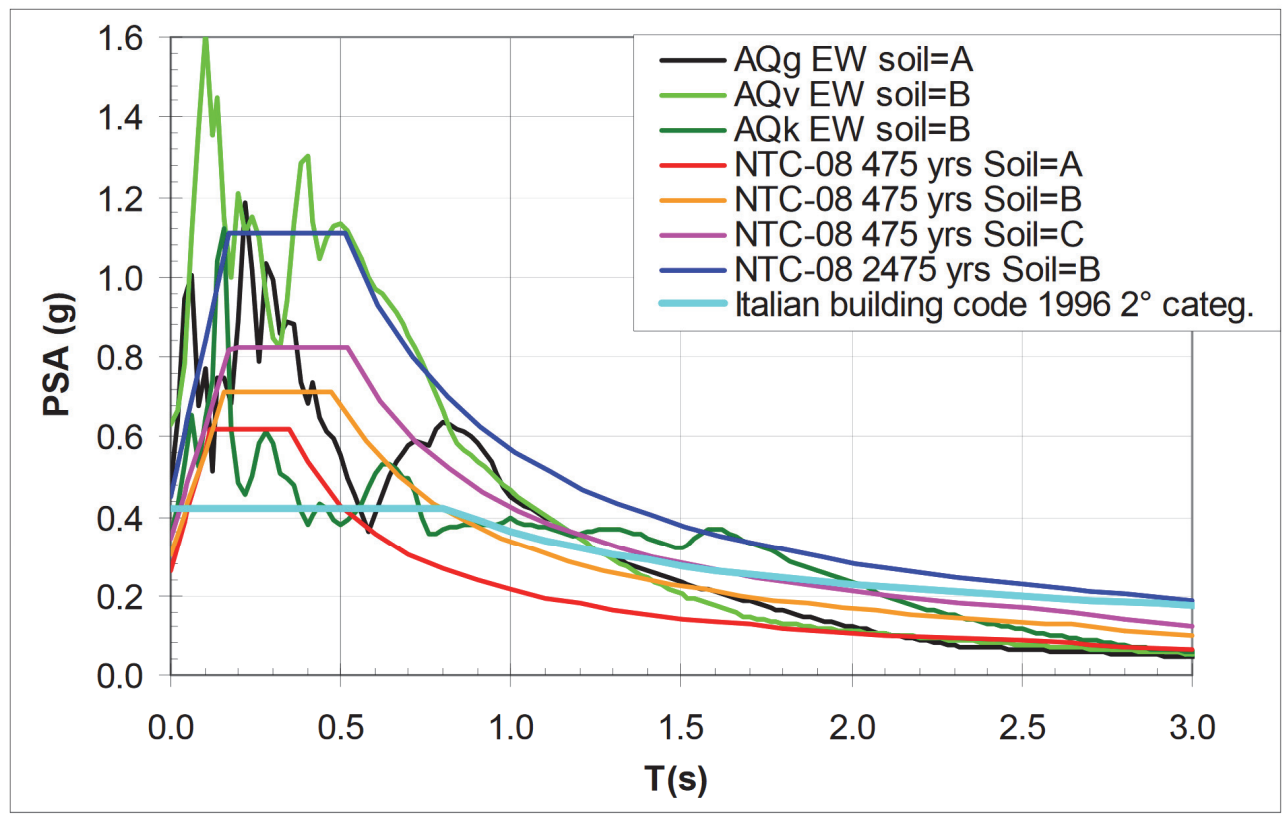

Figure 15: Comparison of the response spectra obtained by the seismic records (accelerometric station AQ=L'Aquila) with the response spectrum provided by the Italian Standards [22].
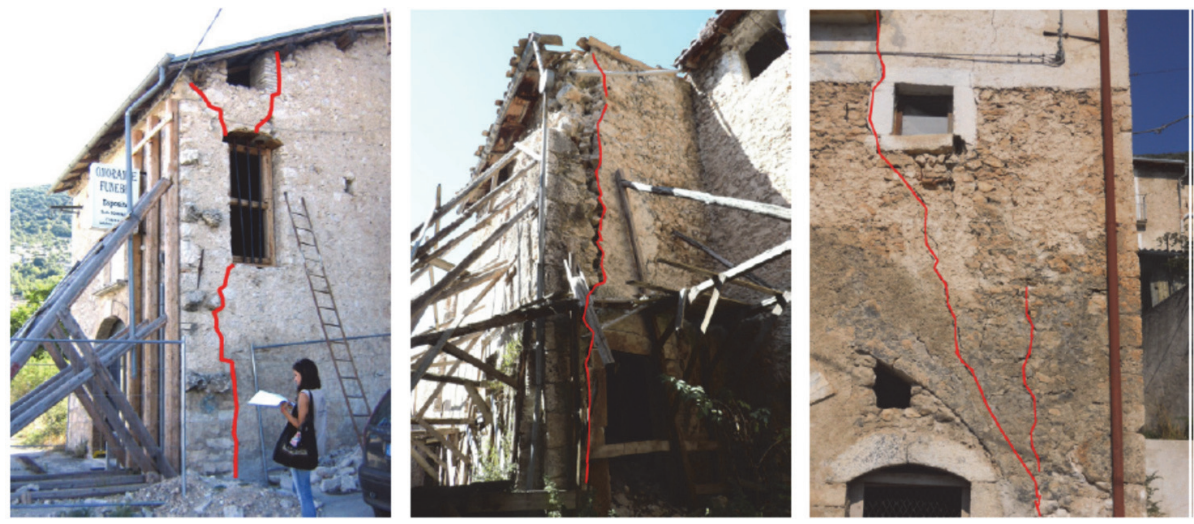

Figure 16: Observed building damage mechanisms, San Pio delle Camere. 


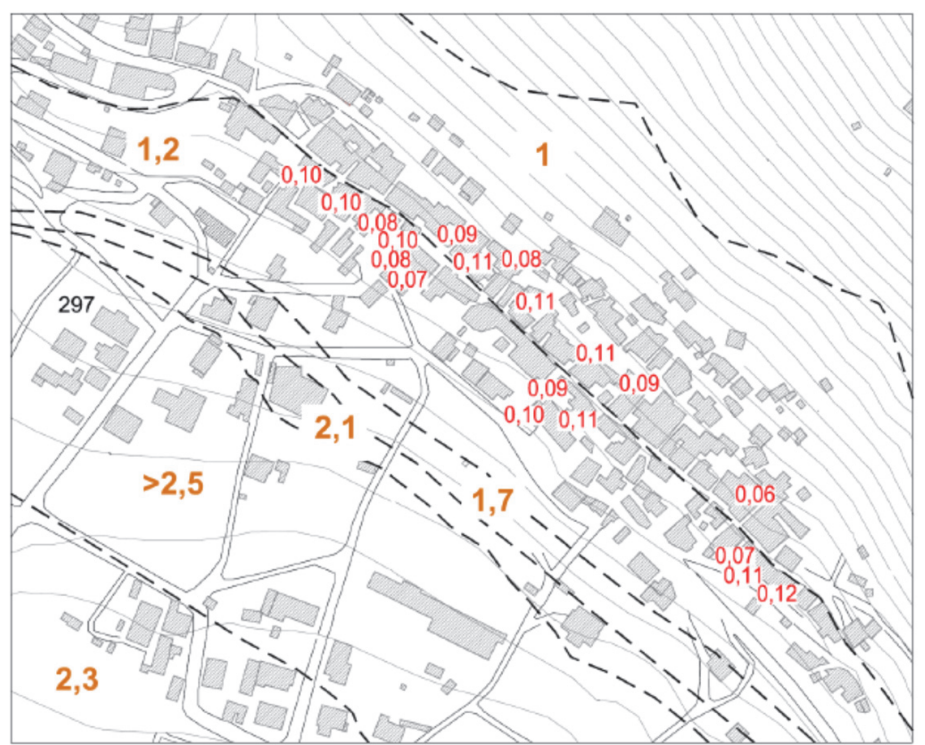

Figure 17: Map of the ground accelerations (a/g) within the historic centre of San Pio delle Camere.

\section{CONCLUSIONS}

7 his paper illustrates the activities performed by civil engineering student interns during two sessions funded by the Tuscany Region. The San Pio delle Camere village, damaged by the 2009 Abruzzo earthquake, was fully surveyed in 2010-2011 by forty interns divided in teams of two or three students. Each survey team stayed in the village for about four weeks in different perdios during 2010-2011. The activities of surveying and analysis have been extremely valuable from a professional and human point of view, giving to the students the opportunity to observe first-hand the consequences of design errors and of improper rehabilitation techniques. This experience also strengthened their empathy and capability of communicating with local authorities and inhabitants, in a complex context.

\section{ACKNOWLEDGEMENTS}

S pecial thanks are due to all the students and tutors who participated in the two campaigns of 2010-2011, the RELUIS Consortium for the support, and the Tuscany Region for funding the internships.

\section{REFERENCES}

[1] Ceradini V. (2003). Codice di pratica per la sicurezza e la conservazione degli insediamenti storici dell'Area Grecanica. Gangemi, Roma.

[2] Andreini, A., De Falco, A. and Sassu, M. (2012). Damage mechanisms in masonry buildings and peak ground acceleration during the 2009 earthquake in Abruzzo (Italy). In: Proceedings of SAHC: 8th International Conference on Structural Analysis of Historical Constructions, Wrocklaw (Lourenco, Modena, Roca eds.), pp. 1755-1764.

[3] Andreini, M, De Falco, A. and Sassu, M. (2012). Damage mechanisms as seismic transducers in historic centres: the example of San Pio delle Camere after 2009 earthquake in Abruzzo (Italy). In: Proceedings of 15th WCEE. Lisboa:15th WCEE, Lisbon, Portugal.

[4] Lagomarsino, S. and Giovinazzi, S. (2006). Macroseismic and mechanical models for the vulnerability and damage assessment of current buildings, Bull Earthquake Eng., 4, pp. 415-443.

[5] Sassu, M. (2011). Studies and surveys on the seismic risk of the historic centre of San Pio delle Camere (AQ), Pisa, ETS Editions, pp. 298.

[6] Sassu, M., Bonannini, E., Cutini, V., De Falco, A., Andreini, M., Giresini, L. and Puppio, M. L. (2015). Il piano di ricostruzione di San Pio delle Camere (AQ), edizioni ETS, Pisa. 
[7] Rovero, L., Alecci, V., Mechelli, J., Tonietti, U. and De Stefano, M. (2016). Masonry walls with irregular texture of L'Aquila (Italy) seismic area: validation of a method for the evaluation of masonry quality, Journal of Materials and Structures, 49, pp. 2297-2314. DOI: 10.1617/s11527-015-0650-2.

[8] Baggio, C., Bernardini, A., Colozza, R., Corazza, L., Della Bella, M., Di Pasquale, G., Dolce, M., Goretti, A., Martinelli, A., Orsini, G., Papa, F. and Zuccaro, G. (2007). Field manual for post-earthquake damage and safety assessment and short term countermeasures (AeDES). In: Pinto AV, Taucer F (eds) European Commission-Joint Research CentreInstitute for the Protection and Security of the Citizen, EUR 22868 EN-2007.

[9] Barbat, A.H., Carreno, M.L., Pujades, L.G., Lantada, N., Cardona, O.D. and Marulanda, M.C. (2010). Seismic vulnerability and risk evaluation methods for urban areas. A review with application to a pilot area. Structure and Infrastructure Engineering, 6(1-2), pp. 17-38.

[10] Dong, L. and Shan, J. (2013). A comprehensive review of earthquake induced building damage detection with remote sensing techniques. ISPRS Journal of Photogrammetry and Remote Sensing, 84, pp. 85-99.

[11] Formisano, A., Marzo, A., Marghella, G. and Indirli, M. (2016). Seismic vulnerability assessment methods applied to the historic built-up of Arsita within the 2009 post-earthquake reconstruction plan. International Journal of Sustainable Materials and Structural Systems, 2 (3), pp. 262-282.

[12] Lourenco, P.B. and Roque, J.A. (2006). Simplified indexes for the seismic vulnerability of ancient masonry buildings. Construction and Building Materials, 20 (4), pp .200-208.

[13] Tertulliani, A., Leschiutta, I., Bordoni, P. and Milana, G. (2012). Damage Distribution in L'Aquila City (Central Italy) during the 6 April 2009 Earthquake. Bull. Seismol. Soc. Am., 102(4), pp. 1543-1553, DOI: 10.1785/0120110205.

[14] Regione Marche, Rilevamento della vulnerabilità sismica degli edifici: istruzioni per la compilazione della scheda di $2^{\circ}$ livello - Muratura, D.G.R. n. 712 del 4 aprile 2001.

[15] Casapulla, C., Giresini, L. and Lourenço, P.B. (2017). Rocking and Kinematic Approaches for Rigid Block Analysis of Masonry Walls: State of the Art and Recent Developments, Buildings 7(3), pp. 69; DOI: 10.3390/buildings7030069.

[16] Giresini, L., Casapulla C., Denysiuk R., Matos J. and Sassu M. (2018). Fragility curves for free and restrained rocking masonry façades in one-sided motion, Engineering Structures, 164, pp.195-213; DOI: 10.1016/j.engstruct.2018.03.003.

[17] Giresini, L. (2017) Design strategy for the rocking stability of horizontally restrained masonry walls, COMPDYN 2017 6th ECCOMAS Thematic Conference on Computational Methods in Structural Dynamics and Earthquake Engineering M. Papadrakakis, M. Fragiadakis (eds.) Rhodes Island, Greece, 15-17 June 2017.

[18] Casapulla, C. and Argiento L.U. (2018). In-plane frictional resistances in dry block masonry walls and rocking-sliding failure modes revisited and experimentally validated. Composites Part B: Engineering 132, pp. 197-213.

DOI: 10.1016/j.compositesb.2017.09.013.

[19] Casapulla, C. and Maione A. (2016). Formulating the torsion strength of dry-stacked stone blocks by comparing convex and concave contact formulations and experimental results. Indian Journal Of Science \& Technology, pp. 1-7. DOI: 10.17485/ijst/2016/v9i46/107346.

[20] Andreini, M., De Falco, A., Giresini, L. and Sassu, M. (2013). Collapse of the historic city walls of Pistoia (Italy): causes and possible interventions. In: Advances in Civil Structures. Applied Mechanics and Materials, 352, pp. 1389-1392. DOI: 10.4028/www.scientific.net/ AMM.351-352.1389.

[21] Giresini, L., Sassu, M., Butenweg, C., Alecci, V. and De Stefano, M. (2017). Vault macro-element with equivalent trusses in global seismic analyses, Earthquakes and Structures, 12(4), pp. 409-423.

[22] Giresini, L. (2015). Energy-based method for identifying vulnerable macro-elements in historic masonry churches, Bulletin of Earthquake Engineering, 14(3), pp. 919-942. DOI: 10.1007/s10518-015-9854-7.

[23] Albarello, D., Boncio, P., Dolce, M., Galli, P., Messina, P., Pace, B., Peruzza, L., Sabetta, F., Sanò, T. and Visini, F. (2009). Input sismico per la microzonazione dell'area interessata dal terremoto de L'Aquila del 6 Aprile 2009, RELUIS. 